\title{
HIVIAIDS Distigmatisation at Work Place: More Than Comprehensive Knowledge Required
}

\author{
Mburu Samuel", Mutuku Irene \\ School of Health Sciences, Kirinyaga University, Kerugoya, Kenya \\ Email address: \\ wsmburu@gmail.com (M. Samuel), imutuku@kyu.ac.ke (M. Irene) \\ ${ }^{*}$ Corresponding author
}

\section{To cite this article:}

Mburu Samuel, Mutuku Irene. HIV/AIDS Distigmatisation at Work Place: More Than Comprehensive Knowledge Required. International Journal of HIV/AIDS Prevention, Education and Behavioural Science. Vol. 3, No. 6, 2017, pp. 63-69. doi: 10.11648/j.ijhpebs.20170306.11

Received: November 20, 2017; Accepted: December 1, 2017; Published: January 8, 2018

\begin{abstract}
According to the National AIDS Control Council (NACC) of Kenya, Human Immunodeficiency Virus/Acquired Immunodeficiency Syndrome (HIV/AIDS) prevention starts and ends with behavior change and anything else comes in between. Importantly, "although antiretroviral therapy (ART) was working, countries will not be able to treat their way out of the HIV/AIDS pandemic, as it is not sustainable in the long run". This highlights the critical role of healthy behavioral change, HIV status awareness, distigmatisation, stopping of new infection, inclusion of key populations, support groups and psychosocial support of people living with HIV (PLWH) in HIV/AIDS management and prevention strategies. Significantly, high levels of HIV/AIDS knowledge do not always translate to a positive behavior change. The purpose of this descriptive survey was to investigate the levels of HIV/AIDS knowledge, awareness, perceptions and attitudes towards the virus and PLWH among members of staff a public university in Kenya. This was a descriptive survey in which all the members of staff (due to the small population of only 288) were targeted as participants, issued with self-administered questionnaire, structured according to the NACC guidelines for public sector. The data was analyzed using descriptive statistics with IBM SPSS version 22 software. Significantly, HIV/AIDS knowledge levels were adequately high as indicated by the $83 \%$ female and $69 \%$ male employees who strongly agreed that the risk of HIV infection can be reduced by having one uninfected partner. Similarly, $60 \%$ females, 58\% males strongly disagreed that mosquitoes could transmit HIV, while 57\% males, $63 \%$ females strongly disagreed that one could get HIV by sharing food with an infected person. However, despite the high HIV/AIDS knowledge, awareness levels, HIV- associated stigma (18\% males \& $10 \%$ females), ignorance of effectiveness of condom in prevention (10\% females \& 7\% males) still persisted. Essentially, if these drawbacks are not decisively dealt with, they will reverse the gains so far achieved in the HIV/AIDS response. These findings are important in informing stakeholders, policy makers such as work place HIV/AIDS policy makers in formulation, implementation, designing healthy behavioral change, HIV status awareness, stopping of new infections, distigmatisation and preventive strategies in workplaces. This will have a direct impact on HIV/AIDS management, prevention and thus help in attainment of the United Nations (UN) Sustainable Development Goal (SDG) number 3 on ensuring health for all, promoting well-being for all at all ages, 90-90-90 strategy and the Kenya's vision 2030 of a HIV free country.
\end{abstract}

Keywords: HIV/AIDS, Attitudes, Perceptions, Awareness, Prevention, Distigmatisation, Behavior Change

\section{Introduction}

According to NACC, (2017) [1], HIV/AIDS prevention starts and ends with behavior change. Essentially, anything else comes in between. Similarly, NACC noted that although ART was working, the Country will not be able to treat her way out of the HIV pandemic, thus underlining the importance of enhancing investment in HIV prevention systems such as positive behavioral change, HIV status awareness, distigmatisation, prevention (e.g. availing and training people in proper and consistent male and female condom use), support groups and psychosocial care of people living with PLWH. Significantly, the highest HIV/AIDS prevalence in Kenyan men is among those between the 45 49 years age bracket. Similarly, 5 out of 100 men between the ages of 50 - 60 years were HIV positive [2]. 
Interestingly, the government of Kenya spends $60 \%$ of its HIV/AIDS budget on providing care and only a meagre $14 \%$ on prevention. Unfortunately, most of the few existing HIV/AIDS prevention strategies have left behind critical groups such as men, adolescents, youth, key populations such as men who have sex with men (MSN), sex workers and people living with disability (PWD). Importantly, HIVassociated stigma has been identified as slowing down the gains made in the fight against HIV/AIDS [1]. The challenge of disclosure of HIV status to partners, spouses, friends and families due to fear of stigmatization and discrimination has prevented infected people from going for testing to know their HIV status. Hence, they continue to transmit the virus to their partner(s) or spouse (s) $[1,2]$. Likewise, men accounted for only $30 \%$ of all the people who had tested for HIV according to WHO, (2016). Supplement Guidelines on HIV testing. For that reason, HIV positive men are less likely to be diagnosed and put on ART. Hence, they continue transmitting the virus and hampering efforts to reduce new HIV infections [3].

Fortunately, the possibility of a HIV free Kenya during our lifetime has been suggested by NACC, (2017) [1]. However, this will only be possible if the Country reduced or stopped new HIV infections by achieving zero transmission. Accordingly, zero transmission can only be realized if everybody gets tested for HIV to know their status, with all HIV positives individuals receiving antiretroviral therapy (ART), suppresses the virus to undetectable levels and the negative ones adopting a positive behavior change $[1,4,5,6]$. However, despite the gains in HIV response by the government, there were 61,000 new HIV infections in Kenya for both males and females in 2016. Notably, this translated to a $21 \%$ reduction of new HIV infections $(77,500)$ in 2016. Significantly, there were 32, 000 HIV/AIDS illnesses-related deaths in 2016. Conspicuously, due to the universal access to ART, HIV patients are no longer dying from HIV-related illnesses, but from non-communicable diseases (NCDs) (NACC, 2017). Accordingly, out of the 1,555,700 (903,600 women, 551, 300 males and 100, 800 children) PLWH in Kenya, 1, 018, 900 or 93\% were on ART by January, 2017 [1].

Importantly, some of the current HIV/AIDS prevention strategies such as abstinence have failed in both Kenya and Uganda [7]. This highlights the need to change the way the country undertakes its policies and strategies. Specifically, despite $64 \%$ of men and $57 \%$ of women in Kenya having a comprehensive HIV/AIDS knowledge, this has not translated into positive behavior change. Subsequently, only $44 \%$ of men classified as having high risk behavior such as having several sexual partners and whose HIV status was not known reported using a condom [1]. In addition, HIV-associated stigma, discrimination and ignorance were still prevalent in the society especially in work places. For that reason, and to consolidate the current gains, a change in strategy to include; scaling up HIV testing for status awareness, distigmatisation efforts, improving quality of care and psychosocial support of PLWH, inclusion of key populations (men, youth, adolescents, MSM, PWD) in future prevention strategies, upscaling investment in HIV prevention systems and reviewing HIV/AIDS curriculum [1].

Surprisingly, the impact of education levels, socioeconomic status, HIV/AIDS knowledge levels, status awareness on positive behavioral change, HIV prevention, distigmatisation, perceptions, attitudes (towards HIV/AIDS, prevention strategies and PLWH) among adults especially in workplaces (where most active adult spend most of their days), have not been exhaustively explored. Therefore, studies to urgently investigate this before HIV-associated stigma and ignorance reverse the gains achieved so far in HIV/AIDS response are needed. In addition, active inclusion and involvement of men in future HIV/AIDS prevention strategies such as HIV testing for status awareness, availing home/self-testing kits, pre-exposure prophylaxis (PrEP) and upscaling provision to individuals at constant risk of HIV infection, training and demonstrations of proper use of condoms (both males \& females) specifically at workplace.

Hence, to investigate the hypothesis that knowledge, awareness levels among members of staff at a public University in Kenya were low, hence impacting negatively on their HIV/AIDS perceptions and attitudes, the authors conducted this descriptive survey. The authors were trying to answer the following questions; what were the staffs' knowledge, awareness levels of HIV/AIDS and its prevention, what was the staffs' perception and attitudes towards HIV/AIDS and PLWH. This paper reports an important finding that comprehensive HIV/AIDS knowledge, awareness levels are not enough to influence positively attitudes and perceptions towards HIV/AIDS, its prevention and PLWH. A lot more is required to influence positively HIV-associated stigma and a health behavioral change to prevent HIV transmission. Consequently, more efforts, specifically targeting previously excluded groups e.g. men such as upscaling of positive behavioral change, HIV/AIDS knowledge, awareness, prevention (e.g. demonstration of proper condom use and its effectiveness), distigmatisation campaigns and HIV testing for awareness by providing home/self-testing kits, which have been shown to be effective in adolescents [8]. Similarly, integrating VCT services with other male specific health services e.g. voluntary medical male circumcision (VMMC), sexuality, reproductive health, sexually transmitted diseases (STDs) programmes is recommended.

\section{Methods}

\subsection{Design}

This was a descriptive survey conducted at a public University in Kenya, Kirinyaga University $(\mathrm{KyU})$ between $1^{\text {st }}$ of February, 2017 to $30^{\text {th }}$ October, 2017, where all permanent and pensionable employees (on the payroll of the university by the time of the survey) were sampled. Kirinyaga University is one of the public Universities in Kenya. It is situated in Sagana-Kutus road in the Kirinyaga County of Kenya. Kirinyaga County has a HIV/AIDS prevalence rate of $3.3 \%$. 


\subsection{Inclusion Criteria}

All permanent and pensionable employees (both males and females) of the University (on the University payroll and with a personal file number $\{$ PF.NO.\} by the time of the survey) were included in the survey. Since the total population of the permanent and pensionable staff were few (only 288 by the time of survey), there was no need of sampling, hence all the employees were included in the survey $(\mathrm{n}=288)$.

\subsection{Exclusion Criteria}

All casuals and part-time employees (not on the payroll and without a PF. No. of the University at the time of the survey), were excluded.

Subsequently, a total of 288 self-administered questionnaires, structured according to NACC-Kenya guidelines for public sector (2015-2016) [9], on conducting descriptive surveys were issued. The questionnaire was structured to capture; personal information (sex, age, employment type, level \& education level); knowledge on HIV/AIDS, prevention; perception, attitudes towards HIV/AIDS, its prevention and PLWH. The questionnaires were pre-tested to review suitability, answerability of the questions and time taken to complete them. An informed consent form detailing the purpose of the survey, any foreseen risk, benefits of the survey (if at all) and protection of privacy (confidentiality guarantee) for participants was attached to the questionnaire. The education level and socioeconomic class as indicated by the type of employment of the participants were also captured. The respondents were requested to go through the consent form and only tick yes (for anonymity) if they agreed to participate in the survey. Out of the 288 questionnaires issued, 132 were returned, representing a response rate of $46 \%$. Out of the 132 study participants, 83 or $62 \%$ were males and 49 or $38 \%$ females. Majority of the participants were either employed as technical or support staff indicating a low to middle socioeconomic status. In addition, majority of the participants had at least a diploma or degree level of education.

\subsection{Data Collection, Analysis and Interpretation}

After explanation and confirmation of understanding of the purpose of the survey, each of the participants was issued with a consent letter with the attached structured selfadministering questionnaire. The participants were requested to read the consent carefully, ensure they understood its content and ask or seek clarification in case of doubts before signing it. After signing the consent letter, participants were requested to complete the questionnaires. The completed questionnaires were coded by assigning each of them a unique number (only identifier) and the information provided by the participants transcribed into SPSS software (IBM version 22). To protect the privacy, ensure anonymity and confidentiality of the participants, the questionnaires' information contained therein after collection, were assigned unique numbers, the only way of identifying them (anonymity). Consenting and dissenting participants were required to only tick "YES" or "NO" on the consent letter. Furthermore, access to the questionnaires and information provided was limited to the two investigators and were stored in lockable cabinets. The data was analyzed using descriptive statistics, summarized into tables and bar graphs as shown below. During analysis stage, the data was stratified into males, females and age bracket to control for confounding effect.

\subsection{Ethical Consideration}

The study was conducted in accordance to the World Medical Association Helsinki Declaration.

\section{Results}

Table 1. Males Perceptions and Attitudes towards HIV/AIDS and PLWH

\begin{tabular}{llllll}
\hline Perceptions\& Attitudes & Strongly Agree & Agree & Disagree & Unsure & I don't Know \\
\hline Laws against Discrimination & $65.1 \%(54)$ & $28.9 \%(24)$ & $6.0 \%(5)$ & $0.0 \%(0)$ & $0.0 \%(0)$ \\
Give Support and Respect & $61.4 \%(51)$ & $36.1 \%(30)$ & $2.4 \%(2)$ & $0.0 \%(0)$ & $0.0 \%(0)$ \\
Employer Reveal & $0.0 \%(0)$ & $6.0 \%(5)$ & $86.7 \%(72)$ & $3.6 \%(3)$ & $3.6 \%(3)$ \\
Working with HIV Colleague & $39.8 \%(33)$ & $47.0 \%(39)$ & $7.2 \%(6)$ & $6.0 \%(5)$ & $0.0 \%(0)$ \\
Homosexual and HIV & $8.4 \%(7)$ & $12.0 \%(10)$ & $74.7 \%(62)$ & $4.8 \%(4)$ & $0.0 \%(0)$ \\
Drug users Sex workers and HIV & $6.0 \%(5)$ & $12.0 \%(10)$ & $74.7 \%(62)$ & $6.0 \%(5)$ & $1.2 \%(1)$ \\
\hline
\end{tabular}

Table 1 shows the percentages and raw numbers of male participants. Majority of males $(87 \%)$ had the right perception towards HIV and PLWH, and would be comfortable to work with HIV positive colleague (i.e. reduced HIV-associated stigma). However, 20\% males agreed that Homosexuals and injecting drug users deserved to be infected with HIV (indicating HIV-associated stigma and discrimination).
Table 2 shows percentages and raw numbers of female participants. Majority of females (88\%) had the right perception, attitude towards HIV and PLWH would be comfortable to work with HIV positive colleague (i.e. reduced HIV-associated stigma). However, $10 \%$ of the females agreed that Homosexuals and injecting drug users deserved to be infected with HIV (indicating HIV-associated stigma and discrimination). 
Table 2. Females Perceptions' and Attitudes towards HIV/AIDS and PLWH

\begin{tabular}{llllll}
\hline Perceptions \& Attitudes & Strongly Agree & Agree & Disagree & Unsure & I don't Know \\
\hline Laws against Discrimination & $69.4 \%(34)$ & $28.6 \%(14)$ & $2.0 \%(1)$ & $0.0 \%(0)$ & $0.0 \%(0)$ \\
Give Support and Respect & $65.3 \%(32)$ & $32.7 \%(16)$ & $2.0 \%(1)$ & $0.0 \%(0)$ & $0.0 \%(0)$ \\
Employer Reveal & $4.1 \%(2)$ & $10.2 \%(5)$ & $83.7 \%(41)$ & $0.0 \%(0)$ & $2.0 \%(1)$ \\
Working with HIV Colleague & $38.8 \%(19)$ & $49.0 \%(24)$ & $6.1 \%(3)$ & $6.1 \%(3)$ & $0.0 \%(0)$ \\
Homosexual and HIV & $0.0 \%(0)$ & $10.2 \%(5)$ & $79.6 \%(39)$ & $6.1 \%(3)$ & $4.1 \%(2)$ \\
Drug users Sex workers and HIV & $4.1 \%(2)$ & $6.1 \%(3)$ & $81.6 \%(40)$ & $4.1 \%(2)$ & $4.1 \%(2)$ \\
\hline
\end{tabular}

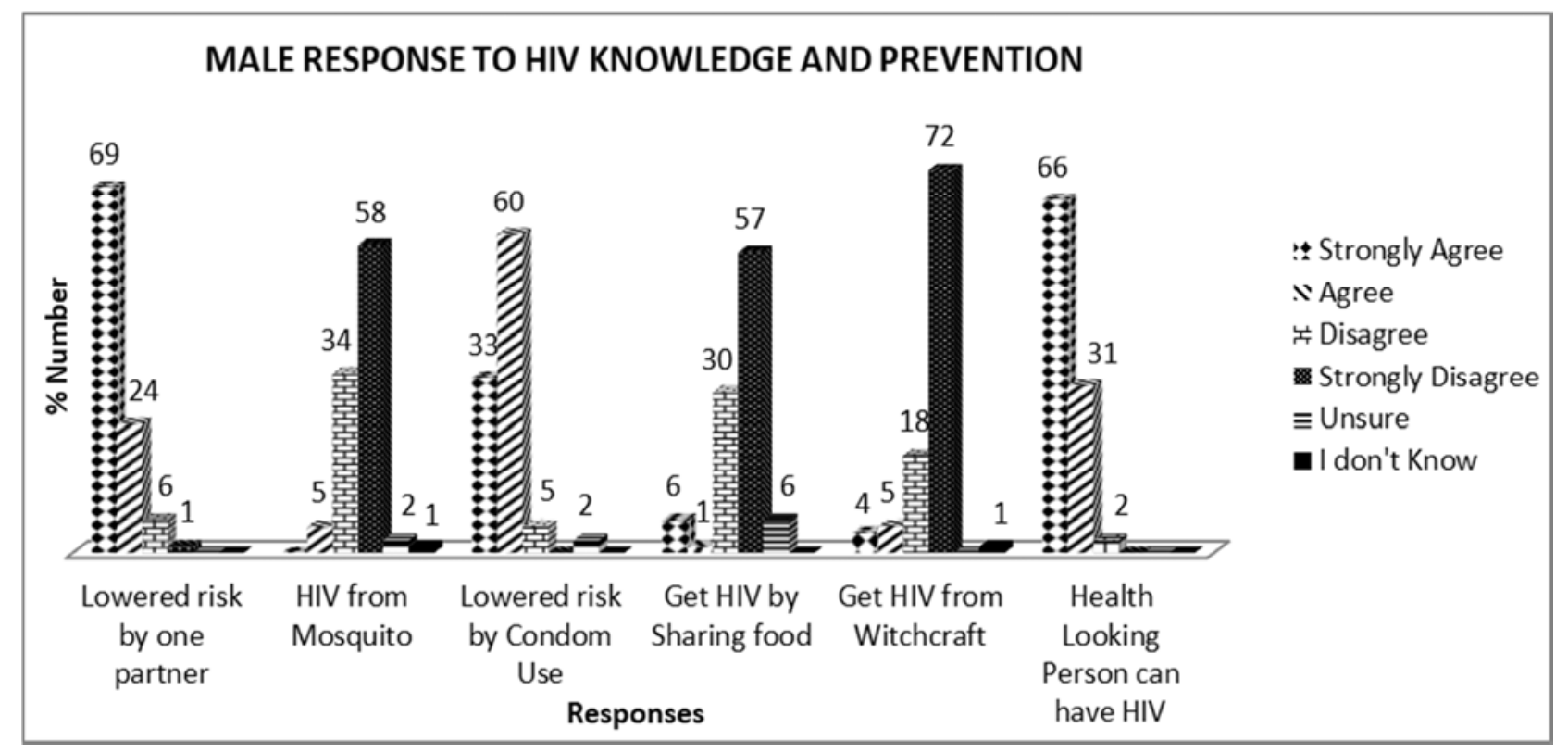

Figure 1. Males Respondents Knowledge Levels on HIV/AIDS and its Prevention.

The figure shows high levels of knowledge of HIV/AIDS transmission and its prevention in male participants.

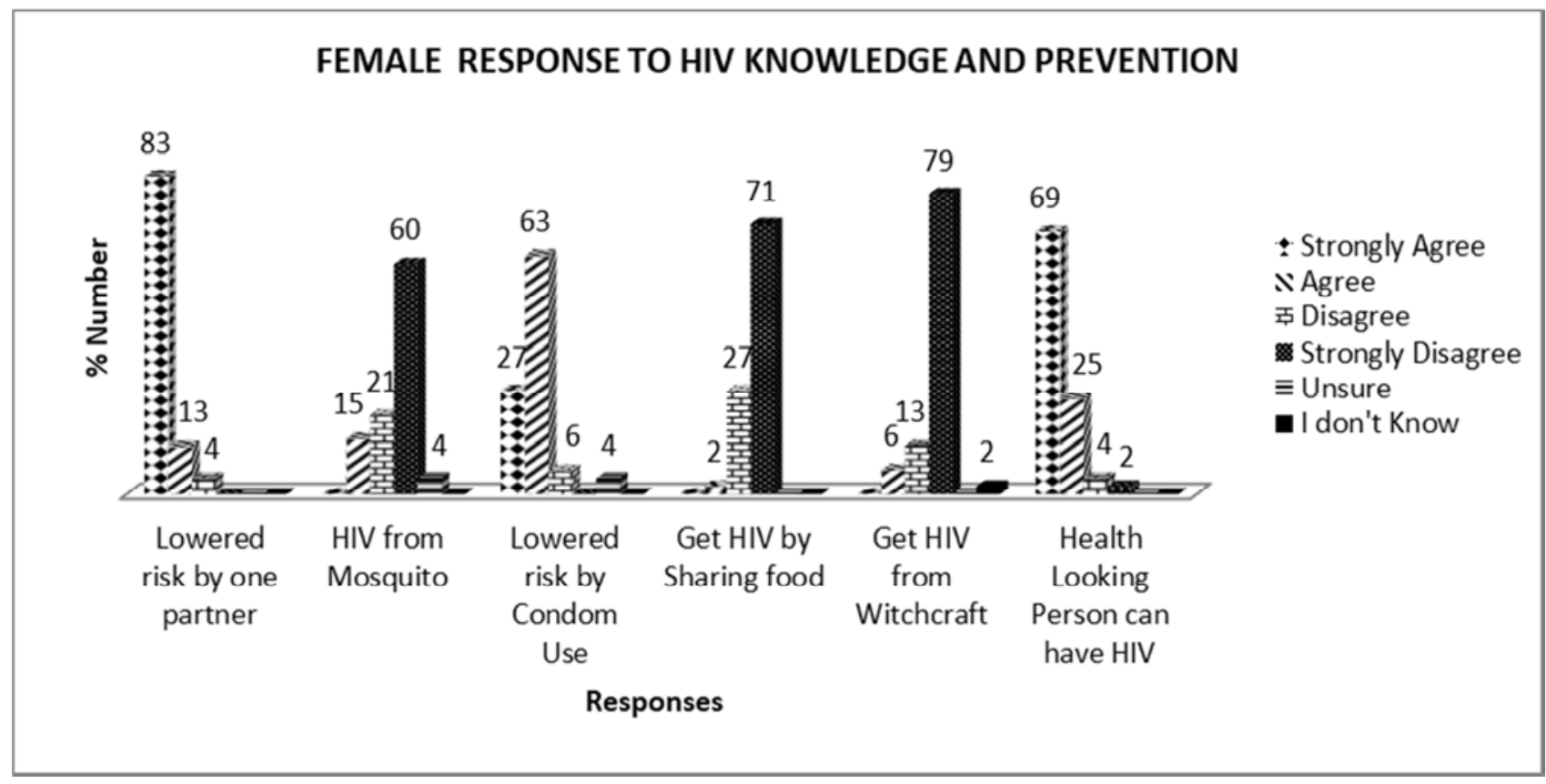

Figure 2. Female Respondents Knowledge Levels on HIV/AIDS and its Prevention

The figure shows the high level of knowledge about HIV/AIDS transmission and its prevention among the female participants. 


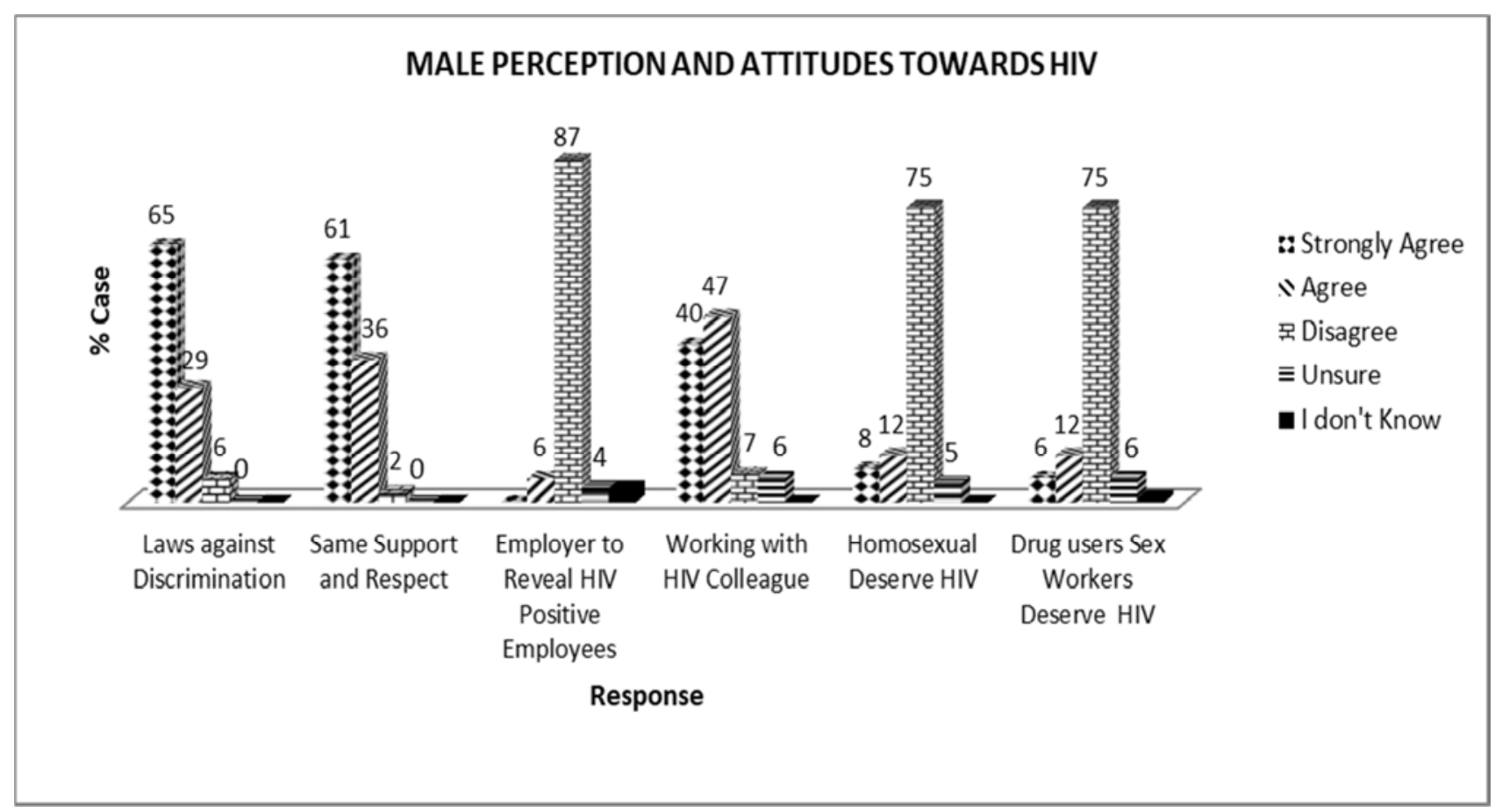

Figure 3. The Male Respondents Perceptions towards HIV and PLWH.

The figure shows that knowledge of HIV/AIDS is high among the members of staff of the University.

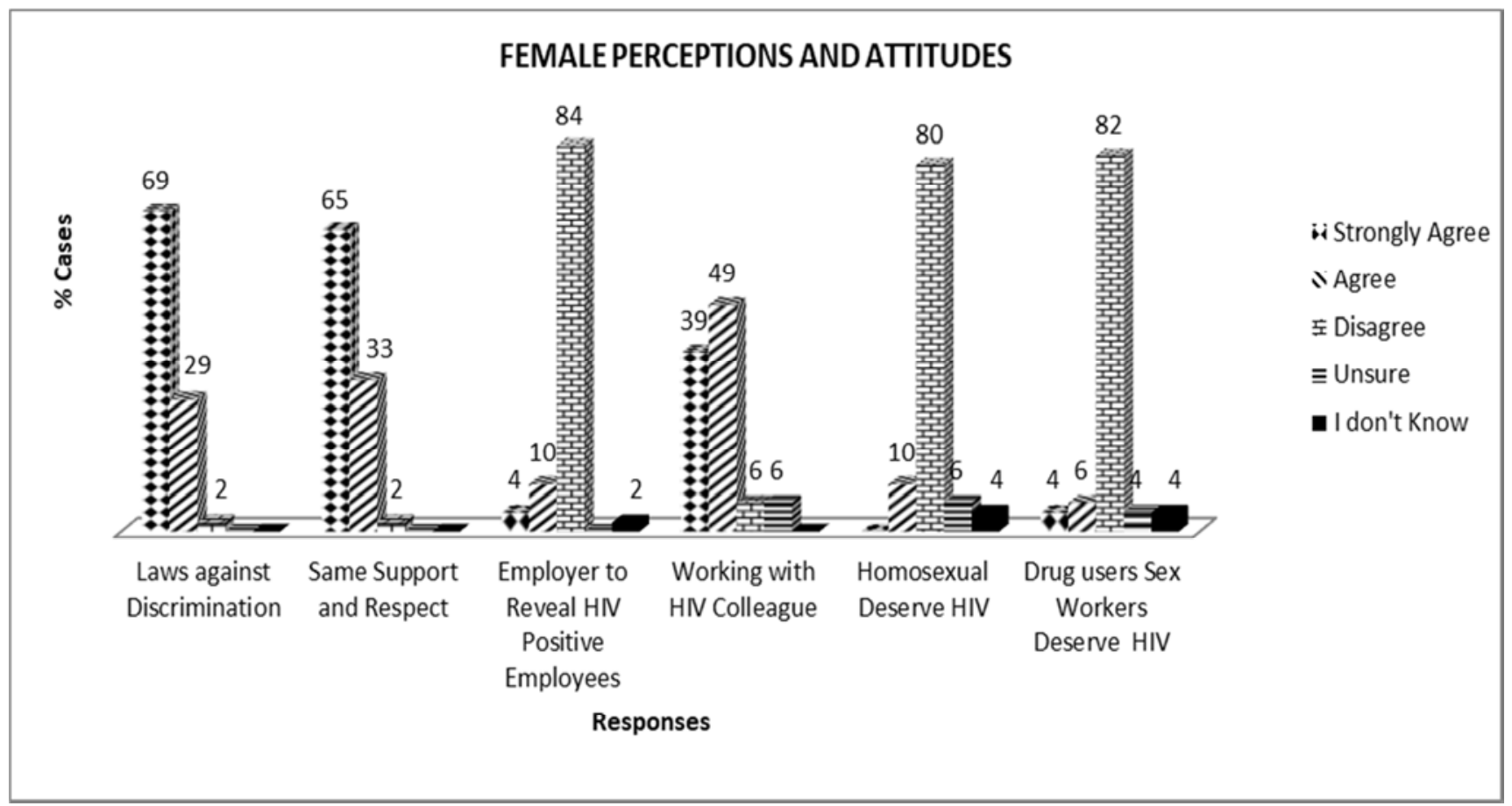

Figure 4. The Female Perceptions and Attitudes towards HIV and PLWH.

Figure 4 shows majority of the females had the right perception and attitude towards HIV/AIDS and PLWH Discussion

\section{Discussion}

The population comprised both male and female permanent employees of the University. The age of the participants was from 25 - 56 years of age, with majority of them in 30-39 years age group, and with at least a diploma or degree level of education. Majority of the participants were either technical staff or support staff, indicating they belonged to low to middle class socio- economic group. The objective of this survey was to investigate HIV/AIDS knowledge levels, perceptions and attitudes of the members of staff towards HIV/AIDS, its prevention and PLWH. 
Although, the HIV/AIDS knowledge levels were generally high, females $(87 \%)$ respondent showed higher levels than their male $(69 \%)$ colleagues as indicated in figure 1 and 2 . Similarly, female respondent's perceptions and attitudes towards HIV/AIDS, its prevention and PLWH, were higher than their male colleagues, which directly correlated with their higher HIV/AIDS knowledge levels (Figure $1 \& 2$ ).

Notably, the participants' knowledge levels on HIV/AIDS, prevention were high. This was highlighted by the high numbers of females (83\%), males $(68.7 \%)$, who strongly agreed that HIV risk could be reduced by having just one uninfected partners, the $60 \%$ females, $58 \%$ males who strongly disagreed that mosquitoes could transmit HIV, the $57 \%$ males and $63 \%$ females who strongly disagreed that one could get HIV by sharing food with an infected person. Similarly and in support of this, $72 \%$ males and $70 \%$ females strongly disagreed that one could get HIV from witchcrafts with further $66 \%$ males and $69 \%$ females strongly agreeing that a healthy looking person could have HIV as shown in figure 1 and 2 . Interestingly, although $60 \%$ male and $63 \%$ female respondents' agreed that consistent, proper use of condom during intercourse reduced the risk of HIV infection, only $32 \%$ males, $27 \%$ females were confident enough to strongly agree. This indicated either, lack of adequate knowledge or training on proper condom use, lingering doubts or ignorance on its effectiveness or suitability or resistance to its use as a HIV prevention tool, which requires more research in the future. Importantly, this was in agreement with findings by NACC [1] on comprehensive HIV/AIDS knowledge, health behavioral change and use of condom for HIV prevention. These results further supports the finding that high levels of HIV/AIDS knowledge does not always translate to healthy behavior as mentioned earlier. Hence, it is recommended that more HIV/AIDS sensitization, awareness campaigns on the correct, consistent use of condom and its effectiveness in HIV prevention are required. In addition, further research on perceptions, attitudes towards use of condom (both male $\&$ females) causes of the lack of confidence in effectiveness of condom in HIV prevention are strongly recommended.

Accordingly, attitudes and perceptions of the respondents were also adequately high as indicated by their level of acceptance of PLWH in figure 3 and 4 . In view of that, $67 \%$ males and $70 \%$ females agreed that the government should put up laws to protect PLWH from discrimination. Similarly, $61 \%$ males and $65 \%$ females strongly agreed that PLWH deserved the same level of support and respect as people with cancer. Likewise, $87 \%$ males and $83 \%$ females' respondents' disagreed with their employer telling them if one of their work colleagues was HIV positive. Equally, 47\% males and $49 \%$ females agreed they felt comfortable working with HIV positive colleague. Nonetheless, only $40 \%$ males and $39 \%$ females were confident enough to strongly agree. This further confirms that despite the comprehensive HIV/AIDS knowledge of the respondents, the current HIV prevention strategies, efforts and campaigns, HIV-associated stigma still persisted. Consequently, this lowered the confidence of the respondents, thus did not strongly agree with the statement. Likewise, ignorance, inadequate knowledge, awareness, perceptions and attitudes towards HIV/AIDS, its prevention and PLWH could have contributed to the low confidence. Importantly, this was in support and agreement with a report by the NACC. This is in support of NACC (2017) [1] call for scaling up of HIV/AIDS knowledge, awareness efforts enhancing investments in HIV prevention systems, status awareness, positive behavioral change, distigmatisation and ending of discrimination of PLWH [1]. Notably, in spite of $75 \%$ males and $80 \%$ females disagreeing that homosexuals deserved to be infected with HIV, of major concern, $12 \%$ males, $10 \%$ females agreed. Out of the $12 \%$ males who agreed, a significant number of $8 \%$ strongly agreed as indicated in figure 1 and 2 . A further, $5 \%$ of males and $10 \%$ females, neither knew nor sure whether homosexuals deserved to get HIV. Essentially, this highlighted inadequate HIV/AIDS knowledge, awareness, ignorance levels, (that HIV was only transmitted sexually), stigma and/or intolerance of "foreign cultures".

A similar trend was noted with regard to perceptions, attitudes towards injecting drug users, sex workers and HIV/AIDS.

According to figure 1 and 2, although $75 \%$ of the males, $82 \%$ of the females respondents disagreed that injecting drug users and sex workers deserved to be infected with HIV, remarkably, $18 \%$ of the males, $10 \%$ females' respondents agreed they deserved to be infected with HIV. Notably, $6 \%$ of the males and $4 \%$ of the females' respondents strongly agreed the group deserved to be infected with HIV. Likewise, $6 \%$ males, $4 \%$ females were not sure, another indication of ignorance, lack of awareness, stigma, conservativeness (to culture and traditions) and intolerance.

An important finding of this descriptive survey was the significant differences between age groups, knowledge, perceptions, attitudes towards HIV/AIDS and PLWH. Interesting, the younger the age group, the higher the HIV/AIDS knowledge (on effectiveness of condom in HIV prevention), perceptions, attitudes such as acceptance, tolerance (of "foreign cultures/traditions") and distigmatization. The many respondents, both males and females who were against their employer revealing HIV status of their colleagues indicated comprehensive HIV/AIDS knowledge and awareness of a need of and implementation of a work place HIV/AIDS policy. However, comprehensive HIV/AIDS knowledge does not always translate to healthy behavior. Hence, the need for increased and consistent HIV/AIDS awareness, sensitization and promotion of positive behavior change among staff at the work place is strongly recommended.

According to the results, PLWH at work places should not be discriminated because of their HIV status and that HIV status of employees should be treated confidentially. Importantly, these findings emphasize the need to scale up HIV/AIDS awareness, sensitization and distigmatisation campaigns. They also support the UN's SDG number three, 90-90-90 strategy $[10,11]$ and Kenya's vision 2030 of 
eradicating HIV by 2030. Fundamentally, HIV status awareness, availing PrEP as a HIV prevention strategy to people at constant risk of infection and the recently launched home/self-testing kits, healthy behavioral change campaigns, HIV prevention (including availing, training in proper and consistent use of both male and female condoms) and distigmatisation efforts at work places will be important and therefore, need to be up scaled.

A limitation of this study was the use of a standard questionnaire developed by NACC, which was limited in scope. Important information regarding HIV status awareness and its influence on health behavioral change could not be captured. The descriptive study was conducted in one institution of higher learning, thus generalization of the findings would be difficult.

\section{Conclusion}

In summary, HIV/AIDS knowledge, awareness levels and its prevention among the participants were high. However, it is also important to note that a high level of HIV/AIDS knowledge does not always translate to a healthy behavior as indicated by the significant number of participants who disagreed on the effectiveness of condom in HIV prevention. In addition, the perception and attitude towards HIV/AIDS and PLWH was adequately high. However, a good percentage $18 \%$ male and $10 \%$ females strongly agreed or agreed that homosexuals, injecting drug users deserved to be infected with HIV. Significantly, this indicated a prevalent HIV-associated stigma, discrimination ignorance, intolerance and conservativeness among the participants, which should be of concern. Again, this indicates that other factors, not just a comprehensive HIV/AIDS knowledge or awareness, which should be explored in future studies are involved and hence required to influence positively perceptions and attitudes in HIV/AIDS, PLWH and HIV prevention. Identification of these factors and how they influence health behavioral change, positive HIV/AIDS, PLWH and HIV prevention among adults in work places will a direct impact on HIV management, prevention and distigmatisation.

\section{Authors' Contribution}

The first author (and corresponding author), M. S, contributed in the concept design, formulation, development of data collection tool (Questionnaires), intellectual input, data interpretation, development and writing of the manuscript. The second author, M. I. contributed in data collection, analysis, interpretation, intellectual input, development and writing of the manuscript (methods and results).

\section{Conflict of Interest}

The authors declare that they have no competing interests.

\section{References}

[1] NACC/MAISHA. 2017. Translating the science to end new HIV infections in Kenya: perspectives, practices and lessons. http://www.iasociety.org/Web/WebContent/File/EduFund_Ken ya_Meeting_Report.pdf. Downloaded on $16^{\text {th }}$ October, 2017 .

[2] NACC. 2016. Kenya AIDS Progress Report. http://nacc.or.ke/wp-content/uploads/2016/11/Kenya-AIDSProgress-Report_web.pdf. Downloaded on $20^{\text {th }}$ February, 2017.

[3] WHO. 2016. Supplementary guidelines on HIV testing. http://apps.who.int/iris/bitstream/10665/251655/1/978924154 9868-eng.pdf. Downloaded on $21^{\text {th }}$ February, 2017.

[4] WHO. (2015). Self-testing helps combat HIV in adolescents.http://www.who.int/features/2015/hiv-selftesting/en/.Downloaded on $24^{\text {th }}$ February 2017.

[5] S. Hosek, et al., Preventing HIV among adolescents with oral PrEP: observations and challenges in the United States and South Africa." Journal of the International AIDS Society, 19. 7, Suppl 6, 2016".

[6] J. S Santelli, I. S Speizer, and Z. R Edelstein, Abstinence promotion under PEPFAR: The shifting focus of HIV prevention for youth. Global Public Health, 8(1), 2013, 1-12.

[7] NACC. 2015. Maisha, NACC, Kenya guidelines for public sector (2015-2016) 12 $2^{\text {th }}$ performance contract (pc) cycle, compliance and certification for prevention of HIV and AIDS infection (MAISHA certification) 2015 - 2016. http://nacc.or.ke/wpcontent/uploads/2015/10/Maisha_1_and_2 Guidelines_for_12 TH_PC_Cylce.pdf http: downloaded on $\overline{2} 8^{\text {th }}$ February, $\overline{2} 01 \overline{7}$.

[8] P Smith, M Wallace, and L. G Bekker, Adolescents' experience of a rapid HIV self-testing device in youth-friendly clinic settings in Cape Town South Africa: a cross-sectional community based usability study. Journal of the International AIDS Society, 19(1), 2016.

[9] R. R Gangakhedkar, Ending AIDS: The 90-90-90 strategy. Medical Journal Armed Forces India, 73(1), 2017, 3-4.

[10] UNAIDS. 2017. 90-90-90. An ambitious treatment target to help end the AIDS epidemic. http://www.unaids.org/en/resources/documents/2017/90-9090. Downloaded on $20^{\text {th }}$ March 2017.

[11] UNAIDS. 2015. Global AIDS Response Progress Report. http://www.unaids.org/sites/default/files/media_asset/JC2702 GARPR2015guidelines_en.pdf. Downloaded on $23^{\text {rd }}$ February, 2017. 